\title{
$O$ estresse gerado pela pandemia como risco para adoecimento mental e físico do músico a partir das neurociências cognitivas
}

\author{
Viviane Louro \\ Universidade Federal de Pernambuco \\ vivianeslouro@gmail.com \\ Fabiana dos Santos Louro \\ Secretaria de Educação de São Caetano do Sul \\ fabislouro@gmail.com \\ Plinio Gladstone Duarte \\ Universidade Federal de Pernambuco \\ pliniogladstoneduarte@gmail.com
}

\begin{abstract}
Resumo: o objetivo deste artigo é mostrar como o estresse gerado pela pandemia pode contribuir no adoecimento de músicos. Para tanto, o embasamento teórico será as Neurociências, que visa compreender o funcionamento do sistema nervoso humano em relação à fisiologia, comportamento, aprendizado e patologias. Neste sentido, será apresentado os motivos que podem levar músicos a desencadearem estresse e as consequências neurobiológicas à saúde física e mental.
\end{abstract}

Palavras-chaves: Estresse, Pandemia, Músico, Adoecimento.

The stress generated by the pandemic as a risk for the musician's mental and physical illness from cognitive neurosciences

\begin{abstract}
The purpose of this article is to show how the stress generated by the pandemic can contribute to the illness of musicians. Therefore, the theoretical basis will be Neurosciences, which aims to understand the functioning of the human nervous system in relation to physiology, behavior, learning and pathologies. In this sense, the reasons that can lead musicians to trigger stress and the neurobiological consequences for physical and mental health will be presented.
\end{abstract}

Keywords: Stress, Pandemic, Musician, Sickness. 


\section{O músico no Brasil e o estresse da pandemia}

A vida do artista brasileiro, em especial a do músico, é cheia de tensões e inseguranças. A profissão do músico talvez seja uma das poucas que exija conhecimento específico em teoria e/ou performance instrumental para poder ingressar na Universidade, o que significa que, quanto mais cedo começar a estudar, mais chances tem de ser inserido na universidade e no mercado de trabalho. Ou seja, o trabalho do músico inicia muito antes de uma profissionalização formal acadêmica, o que, por vezes, pode ser cansativo.

Muitas horas de estudos, disciplina rigorosa, pressão de professores, competitividade, ansiedade na hora de apresentações públicas, insegurança com o mercado de trabalho, desvalorização da profissão e falta de incentivo governamental são algumas das questões presentes diariamente na vida de um músico. Além disso, problemas físicos por excesso de estudo ao instrumento, falta de rotina (no caso de músicos performáticos que tocam "na noite" ou fazem turnês), falta de tempo (para conciliar vida pessoal, com estudos e profissão) e necessidade de altos investimentos financeiros para aquisição de bons instrumentos musicais ou para fazer aulas com renomados professores, também são elementos "corriqueiros" na vida de um músico (BRITTO, 2019).

Tudo isso faz com que a realidade de um estudante de música ou músico profissional, em nosso país, seja por si só extremamente estressante. Britto (2019, p. 19) coloca: "a vida do músico é repleta de pressões quanto ao resultado esperado durante seu processo de estudo". Em relação aos estressores [...] os estudantes de música estão mais suscetíveis a grande quantidade destes, podendo afetar a saúde e o bem-estar mental".

Como se não bastasse o quadro acima apresentado, nos últimos anos, tem se estreitado as possibilidades de trabalho na área cultural/artística devido a constantes mudanças no cenário econômico. No Brasil, apenas $0,21 \%$ da verba orçamentária é destinada a manutenção e fomento da cultura e arte. Segundo o Sistema de Informação e Indicadores Culturais de 2019: “A participação do setor nos gastos do governo federal em relação ao orçamento total caiu de $0,08 \%$ em 2011 para $0,07 \%$ em 2018. Já os governos estaduais reduziram de $0,42 \%$ em 2011 para $0,28 \%$ em 2018 e os municípios diminuíram de 1,12\% em 2011 para 0,79\% em 2018” (IBGE, 2019). Diante desse cenário, os trabalhadores da arte precisam, muitas vezes, se dividir em diversos locais de trabalho 
ou mesmo em diversas funções para conseguir renda suficiente para sua sobrevivência. Segundo Calabre:

\begin{abstract}
O ano de 2020 tem início com o setor cultural lutando tanto contra a diminuição drástica de investimentos federais de aplicação direta pela agora Secretaria Especial da Cultura quanto contra a tentativa de esvaziamento dos recursos que circulavam por meio das leis federais de incentivo - um mecanismo de mercado que foi duramente atacado por muitos dos seguidores do atual governo a partir de um discurso criminalizador do fazer cultural (CALABRE, 2020, p. 9).
\end{abstract}

Além de todos os impasses que a categoria artística encontra no país, pelo vírus da "intolerância, do autoritarismo, do obscurantismo e do conservadorismo" (CALABRE, 2020), ainda estamos em um contexto pandêmico, em decorrência do Coronavírus (COVID-19) que assolou o mundo e ainda continua em circulação e aparentemente, ainda longe de ser totalmente extinguido. A pandemia do COVID-19 impactou diversos setores da economia e da saúde pública. Um dos setores mais atingidos foi o da cultura que precisou fechar casas de shows, teatros, cinemas, escolas de artes e cancelar, repentinamente, todas as suas atividades.

A imponente pandemia fez com que diversas iniciativas artísticas/culturais surgissem nas redes sociais (lives, canais de vídeos, festivais musicais on-line etc.), bem como, sacadas de prédios e casas foram transformadas em palco a fim de amenizar os impactos do isolamento e do distanciamento social em diversas partes do mundo. No entanto, como a partir deste contexto, artistas se sustentarão financeiramente, uma vez que essas iniciativas tendem a não ser remuneradas? Apesar da arte ter papel fundamental na manutenção da saúde mental como "escape da solidão, alimento da alma, alento e esperança" (CALABRE, 2020) como estão àqueles que sustentam suas famílias com a arte?

Uma pesquisa foi realizada em 2020 pela plataforma do mercado musical - a "Encore Musicians", do Reino Unido. Os dados apontaram que, devido a pandemia, 64\% dos músicos entrevistados pensam em abandonar a profissão musical e que, em média, perderam 11.300 libras com o cancelamento dos shows (perda de $87 \%$ de renda que dependia de trabalhos ao vivo); $41 \%$ dos entrevistados não receberam auxílio do governo, $40 \%$ se candidataram a trabalhos que não tem relação com música, além de destacar 
desigualdade de gênero, pois mulheres tiveram neste período 34\% menos shows agendados do que os homens (BACON, 2020) ${ }^{1}$.

Além das problemáticas enquanto ao músico performer, é importante ressaltar a adaptação que os educadores musicais tiveram que passar para transformar suas aulas presenciais em aulas remotas. Foi necessário aquisição de novos equipamentos de captação de áudio e vídeo, além da necessidade de desenvolvimento, em tempo recorde, de habilidades para edição de vídeos/áudios, postagens e engajamento nas redes sociais. Tudo isso fez com que muitos precisassem sair de sua zona de conforto, causando mais ansiedade e estresse.

Pela especificidade de seus conteúdos, o ensino remoto emergencial de música torna-se ainda mais desafiador. É válido observar que as plataformas de videoconferência que estão sendo usadas para as aulas virtuais não foram concebidas para atividades e performances musicais, apresentando problemas de latência, fidelidade sonora e sincronização. Além do mais, os equipamentos para uma boa captação de áudio têm um custo bastante elevado, não sendo acessíveis para a maioria dos professores (BARROS, 2020, p. 295).

Somado à crescente tensão em relação ao mercado de trabalho do músico durante a pandemia, bem como, a todos os fatores estressores que já são comuns na rotina de um músico (já relatados), com a flexibilização do isolamento social (que se deu início em meados do segundo semestre de 2020), os músicos estão tendo que se atentar para mais uma questão: as particularidades do exercício de cada área da música (orquestras, corais, aulas, etc.) no que tange aos cuidados com a saúde e prevenção de contágio do vírus.

\footnotetext{
${ }^{1}$ Informação tirada do site London Jazz News
} 
Com o desconfinamento gradual iniciado a 6 de maio de 2020 (na Alemanha), reabertura que varia consoante a província, tem sido cada vez maior o número de músicos, quer profissionais quer amadores, a colocar questões urgentes sobre as condições de reabertura das atividades musicais. [...] Os tipos de questões que surgiram são comuns e de âmbitos semelhantes para músicos de diferentes estilos musicais. Questões particularmente relevantes surgiram no que diz respeito às precauções a tomar no âmbito do ensino do canto e de um instrumento musical em conservatórios, escolas de música e noutras instituições de ensino. Com o aumento progressivo do número de pessoas que se começam a agrupar após o confinamento, aumentam também as questões particulares sobre qual o tamanho que as orquestras, bandas e big bands podem ter. Isto aumenta a complexidade de questões a serem consideradas. Especialmente para músicos profissionais, existem questões de comparabilidade com outras situações laborais semelhantes. Por exemplo: até que ponto o risco de contrair a COVID-19 quando se trabalha num escritório amplo diverge de uma situação de um espaço de ensaio para uma orquestra. A abertura de espaços de concerto ao público em geral levanta igualmente dúvidas e preocupações (SPAHN e RICHTER, 2020, p. 2).

Ou seja, os músicos precisam voltar a trabalhar, mas ao mesmo tempo, o perigo de contágio é grande, considerando que dificilmente músicos atuam em locais sem aglomeração (seja de público ou de seus pares). Sendo assim, muitos protocolos de segurança são necessários, principalmente para músicos que atuam com canto e instrumentos de sopro, uma vez que a via aérea é a principal forma de contágio do vírus. Essa realidade é altamente estressante, pois traz muita vulnerabilidade e instabilidade emocional. Diante disso, cabe uma indagação: quais os possíveis impactos que o estresse de toda essa situação que estamos vivendo pode gerar na saúde mental do músico?

De acordo com a publicação "Depression and other common mental disorders: global health estimates", a depressão atinge 5,8\% da população brasileira (11.548.577). Já distúrbios relacionados à ansiedade afetam 9,3\% (18.657.943) das pessoas que vivem no Brasil, sendo considerado o país mais ansioso do mundo, conforme a Organização Mundial da Saúde (OMS, 2017).

Dados da Organização Mundial de Saúde (OMS) apontam que a prevalência mundial do transtorno de ansiedade (TA) é de 3,6\%. No continente americano esse transtorno mental alcança maiores proporções e atinge 5,6\% da população, com destaque para o Brasil, onde o TA está presente em $9,3 \%$ da população, possuindo o maior número de casos de ansiedade entre todos os países do mundo. Essas estatísticas são reflexos da dinâmica da sociedade moderna, que contribui para o surgimento de transtornos mentais e comportamentais, sobretudo a ansiedade, o estresse e a depressão, que se tornaram doenças muito comuns nos consultórios médicos (FERNANDES et al., 2018, p. 2345). 
$\mathrm{Na}$ atual conjuntura, a OMS já publicou atualizações a respeito da ansiedade no mundo em decorrência da pandemia. Alguns grupos são os mais afetados, como profissionais da saúde que estão na linha de frente do combate contra o vírus, mulheres que precisam conciliar o trabalho em casa, serviços domésticos e educação dos filhos, crianças com deficiências e pessoas que trabalham em locais lotados e na rua. O aumento do álcool foi significativo entre pessoas de 15 a 49 anos e a diminuição dos serviços em saúde mental colaboraram para esse quadro, conforme levantamento da Organização PanAmericana de Saúde (OPAS, 2020).

\begin{abstract}
Queixa número um na contemporaneidade, a ansiedade é ainda mais soberana entre as demandas emocionais no atual momento de pandemia mundial. O distanciamento social vem despertando medo - a emoção básica que respalda a ansiedade. Muito medo está sendo sentido pelas pessoas. E de variados tipos: das mudanças, do futuro, de "não dar conta", da escassez, do imprevisível, do desconhecido, de perder algo ou alguém, da morte... (CHIQUETTI, 2020, p. 33)
\end{abstract}

Segundo Noal e Damásio (2020, p. 1): “estima-se, que entre um terço e metade da população exposta a uma epidemia pode vir a sofrer alguma manifestação psicopatológica, caso não seja feita nenhuma intervenção de cuidado específico para as reações e sintomas manifestados." Mas, como o estresse gerado por situações extremas, como a que estamos vivenciando desde o início de 2020, se relaciona com o adoecimento das pessoas? Há uma explicação físiológica de como o estresse pode impactar nosso organismo? Temos como prevenir o adoecimento causado pelo estresse?

Nesse sentido, as neurociências podem nos ajudar a compreender nossas emoções e o impacto positivo e negativo que elas podem causar em nossas vidas, bem como, nos oferecer caminhos para lidarmos melhor com o momento presente. 


\section{O estresse e suas consequências a partir das neurociências cognitivas}

O termo estresse se origina na física e significa pressão ou constrição de natureza física. Foi o endocrinologista Hans Selye que importou esse termo para tentar descrever a ideia de uma ameaça real ou potencial ao equilíbrio do organismo (JOCA et al., 2003). Quando uma pessoa passa por um estresse crônico pode desenvolver a Síndrome de Adaptação Geral (SAG). Esta síndrome também foi nomeada por Hans Selye como oriunda do estresse e em um de seus artigos ele cita: "todos sabem o que é o estresse, mas, ninguém sabe o que é estresse" (SELYE, 1973, p. 692). Ou seja, o estresse está presente em nosso dia a dia, em cada ação e movimento, tanto físico quanto mental ou como coloca Britto (2019) "o estresse é um estímulo "não especificado", que vem a favor ou contra o nosso organismo, no qual haverá uma reação de alerta, defesa ou adaptação". Valle (2011, p. 42) completa:

O estresse envolve um processo de adaptação do indivíduo às demandas externas e internas, representadas por diversas contingências do cotidiano e pela interpretação das demandas externas, que ocorre em processos cognitivos individuais, com diferentes respostas. O estresse é um fenômeno que ocorre na busca do organismo pela adaptação, assunto que desafia a compreensão do comportamento humano ao longo da história.

O estresse é importante para nossa sobrevivência, pois nos deixa alerta diante dos desafios. Mas, como tudo na vida depende de equilíbrio, a persistência e a intensidade exagerada do estresse pode ser um alto fator de risco para o organismo, podendo gerar doenças tanto físicas quanto mentais. Do ponto de vista das neurociências, precisamos compreender que para o cérebro não existe emoções positivas e/ou negativas, saudáveis e/ou adoecedoras. Na verdade, todas as emoções servem para nos ajudar a sobreviver, mesmo àquelas que nos incomodam profundamente. Como diz o ditado popular: $a$ diferença entre o remédio e o veneno é a dose, sendo assim, é o desequilíbrio entre as emoções que podem nos causar danos e não a existência ou não de uma emoção específica, como exemplifica Chiquetti (2020, p. 33):

O medo em si não é positivo nem negativo. É sim uma emoção estrutural, a serviço da sobrevivência, que nos instiga a lutar ou fugir em situações de perigo. Como esse medo é regulado internamente, em nossa subjetividade, é que determina se essa emoção nos protegerá nos riscos iminentes ou nos bloqueará na vida.

O cérebro é o órgão que operacionaliza nossa cognição, emoção e ação; é ele que possibilita estarmos e agirmos no mundo. O principal objetivo desse órgão é fazer com 
que sobrevivamos e passemos nosso gene para que a espécie se perpetue e para isso, ele precisa se adaptar às demandas do ambiente. "O cérebro humano é um órgão altamente especializado para a adaptabilidade e a resiliência que se molda e se constrói para capacitar a pessoa a fazer frente às vicissitudes e, de igual modo, investir nos desafios que vai tendo ao longo da vida" (VASCONCELOS, 2017, p. 37).

Portanto, precisamos compreender que o estresse, que a maioria das pessoas estão passando nessa época de pandemia, nada mais é do que um mecanismo de defesa de nosso sistema nervoso em busca de uma adaptação para a sobrevivência. De qualquer forma, por mais normal que seja o estresse e sentimentos como ansiedade, desânimo, tristeza e medo, como já dito, quando em excesso, essas emoções podem ser altamente adoecedoras.

Nós somos uma orquestração química, ou seja, as emoções servem como gatilhos para a liberação de hormônios em nosso organismo e, assim como não podemos colocar um eletrodoméstico de 110 volts em uma tomada de 220 volts (pois o equipamento não suporta tanta voltagem), nosso corpo não aguenta receber uma carga química maior do que foi programado geneticamente. Isto significa que o excesso de hormônios ligados ao estresse pode levar aos Transtornos Mentais Comuns (TMC) que segundo Graner e Cerqueira (2019, p. 1328) são “estados mistos de depressão e ansiedade, caracterizados pela presença de sintomas como insônia, fadiga, irritabilidade, esquecimento, dificuldade de concentração e queixas somáticas". Mas, sob o aspecto neurobiológico, como o estresse pode contribuir para o desenvolvimento de um transtorno mental?

Hans Seyle (1952) relata três fases do estresse, sendo a primeira a fase de alerta, onde ocorre aumento da frequência cardíaca e da pressão arterial, contração do baço, liberação de glicose pelo fígado, redistribuição sanguínea da pele para o fortalecimento dos músculos, aumento da frequência respiratória, dilatação dos brônquios e das pupilas e aumento dos linfócitos na corrente sanguínea. Isso tudo gera a reação de luta ou fuga, natural do estresse. A segunda fase é a de defesa ou resistência, na qual há elevação das secreções adrenocorticais, produzindo aumento da pressão sanguínea e da temperatura do organismo, com manifestações de alergias, cansaço, queda na produtividade, hipertensão, agressividade, depressão, distúrbios gastrointestinais e problemas de memória, conforme o pesquisador. A terceira fase é da exaustão, quando há adoecimento profundo dos órgãos 
que foram mobilizados na fase 1 e 2 e quando isso acontece significa que houve falha no processo de adaptação do organismo, podendo levar até à morte (VALLE, 2011).

Nos atendo mais especificamente à fase 2 , do ponto de vista neuroquímico, o principal agente do estresse é o hormônio cortisol, liberado pela glândula supra-renal, como consequência da ativação do eixo hipotálamo-hipófise-adrenal (HPA) ${ }^{2}$ (ALHEIRA e BRASIL, 2005). O hipotálamo é uma região que fica entre o cérebro e o tronco cerebral (figura 1) e é responsável por muitas funções, sendo uma delas, a regulação endócrina de nosso organismo (KANDEL et al., 2014). Sendo assim, quando estamos estressados, o hipotálamo libera uma mensagem para que a glândula supra-renal (que fica sobre os rins) lance em nossa corrente sanguínea hormônios ${ }^{3}$, tais como o cortisol e a adrenalina. São esses hormônios que preparam nosso corpo para reagir ao estresse (LENT, 2010).

Figura 1 - Corte Sagital (de perfil) do encéfalo; Áreas que participam da ativação do sistema de alerta (chamado de Sistema Simpático) (Ilustração feita por Viviane Louro).

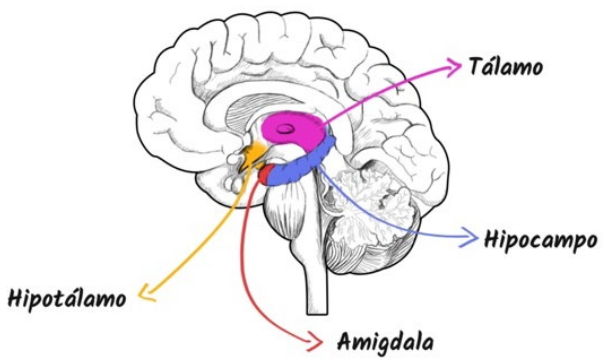

Fonte: Elaboração dos Autores.

O cortisol serve para preparar o organismo para desafios fisiológicos ou ambientais. A persistência e a intensidade exagerada do cortisol em nosso sistema podem tornar hiperreativo o eixo HPA, com prejuízos potenciais ao organismo (JOCA, 2003). Como coloca Britto (2019, p. 31): “[...] se o sistema lançar o cortisol em excesso na corrente sanguínea, com o passar do tempo, este hormônio irá afetar o hipocampo fazendo com que ele

\footnotetext{
${ }^{2} \mathrm{O}$ eixo hipotálamo-hipófise-supra-renal (HHSR) corresponde a um sistema regulador que integra funções endócrinas e neurológicas (ALHEIRA E BRASIL, 2005).

${ }^{3}$ Os hormônios são neurotransmissores que contribuem para a homeostasia do organismo. Como exemplos têm-se a serotonina e adrenalina (hormônios do prazer), cortisol (hormônio do estresse), melatonina (hormônio do sono), dentre outros. Os hormônios são produzidos pelas glândulas suprarrenais, localizadas no sistema endócrino, e têm a função de regular o metabolismo (processamento) de carboidratos, proteínas e lipídeos, estabilizando a pressão arterial e os níveis de açúcar, o que resulta no controle do estresse (BRITTO, 2019).
} 
diminua sua função sensivelmente". O hipocampo é uma estrutura situada no sistema límbico (Fig. 1) e é responsável pelo gerenciamento de nossa memória consciente. Rozenthal et al. (2004) argumentam que a alteração de memória está relacionada a uma desregulação do eixo hipotálamo-hipófise-adrenal, levando a efeitos adversos de hormônios do estresse (cortisol) sobre o hipocampo. Sendo assim, quando nosso sistema está com excesso de cortisol, a longo prazo, podemos começar apresentar problemas de memória. Isso significa que nossas emoções impactam diretamente na cognição e por consequência, no aprendizado.

\begin{abstract}
Sabe-se, com base em diferentes resultados, que há uma profunda integração entre os processos emocionais, os cognitivos e os homeostáticos [...]. Assim, reconhece-se que as áreas cerebrais envolvidas no controle motivacional, na cognição e na memória fazem conexões com diversos circuitos nervosos (ESPERIDIÃO-ANTONIO, 2008, p. 56).
\end{abstract}

Contudo, o impacto do estresse não é somente na memória. Consoante Fontana (1991), o estresse excessivo pode também diminuir a atenção e concentração e aumentar o índice de erros em tarefas propostas, além de contribuir para a demora na reação a estímulos. Assim sendo, o rendimento musical de uma pessoa pode diminuir significativamente diante de fatores estressores (como o da pandemia, por exemplo), uma vez a que performance musical depende de atenção, concentração, memória, dentre outras habilidades mentais.

O estresse em excesso não causa danos somente às questões cognitivas. Joca (2003, p. 47) entende que "[...] o estresse é um dos principais fatores ambientais que predispõem um indivíduo à depressão. Em cerca de $60 \%$ dos casos, os episódios depressivos são precedidos pela ocorrência de fatores estressantes". Como apontam Teng e Panpanelli (2015), a depressão é um dos maiores fatores de risco para o suicídio. Achados científicos verificaram que a glândula adrenal (que secreta o cortisol), em pessoas que se suicidaram, é maior e mais pesada e que o comportamento suicida está ligado a hiper-reatividade do eixo hipotálamo-hipófise-adrenocortical (HPA) (o mesmo sistema responsável pela liberação do cortisol). Essa alteração aumenta o risco de suicídio em 14 vezes:

Como este sistema hormonal relacionado ao cortisol é o principal efetor da reação ao estresse agudo e crônico, e a sua hiper-ativação está associada a uma neurotoxicidade importante, esta alteração biológica é de grande importância na caracterização de uma parte significativa dos pacientes suicidas (TENG e PAMPANELLI, 2015, p. 45). 
O estresse também se relaciona diretamente com a ansiedade, que é uma variação do medo (CHIQUETTI, 2020). O medo é uma das emoções mais primitivas que temos, pois é ele que nos protege do perigo. Sem o medo certamente não teríamos chegado aonde chegamos como espécie:

\begin{abstract}
Quando nosso sistema de alerta está muito ativo, hormônios como adrenalina, noradrenalina e cortisol estão sendo produzidos em altas dosagens pela glândula suprarrenal, e com isso nosso comportamento é alterado: temos vontade de fugir, de lutar ou, então, ficamos paralisados de medo. Esse mecanismo nos acompanha desde os primórdios das civilizações, e atua em nosso sistema como algo totalmente automático e primitivo, pois se trata de um processo neurológico de adaptabilidade para nossa evolução (LOURO, 2020, p. 45).
\end{abstract}

Neurologicamente, o medo está diretamente ligado ao Sistema Límbico, mais especificamente à amígdala (figura 1), que:

[...] é responsável pela detecção, geração e manutenção das emoções relacionadas ao medo, bem como pelo reconhecimento de expressões faciais de medo e coordenação de respostas apropriadas a ameaça e ao perigo" [...] A estimulação da amígdala pode levar a um estado de vigilância ou atenção aumentada, ansiedade e medo (ESPERIDIÃOANTÔNIO, p. 60).

Logo, diante da eminência do perigo, a amígdala dispara sinais para que possamos nos preparar para lidar com a situação (fugir ou lutar). Como já colocado no início deste artigo, a pandemia trouxe instabilidade à nossa rotina: não sabemos como será o futuro, podemos a qualquer momento nos contaminarmos com o temido vírus, temos medo de perder pessoas amadas para a doença, muitos perderam o emprego, alguns perderam entes queridos, fomos obrigados repentinamente a mudar a rotina presencial para a virtual sem que saibamos direito mexer nas ferramentas necessárias, dentre outras questões. Tudo isso faz com que fiquemos em contínuo estado de alerta, mesmo que não percebamos, o que a longo prazo, pode prejudicar sensivelmente nosso organismo, pois quando a amigdala está ativa, significa que nosso organismo está sendo inundado por hormônios específicos para reagirmos ao medo.

O medo faz com que nosso cérebro fique hiperativo tentando se proteger do perigo. Portanto, a ansiedade faz com que tenhamos pensamentos antecipatórios (geralmente negativos ou catastróficos - uma tentativa de prever o futuro e se preparar para sobreviver à ele), além de uma série de desencadeamentos de sintomas fisiológicos e emocionais que podem prejudicar a vida social. "Os transtornos de ansiedade podem aumentar a chance 
de desencadear doenças cardiovasculares, obesidade e diabetes, além de ganho de peso, gordura abdominal e aumento da pressão arterial" (GUERRA, 2020, online).

Além disso, a ansiedade contribui para alteração do sono e este é fundamental para o equilíbrio de nosso organismo, saúde física e mental. Consoante Valle (2011), o sono tem função protetora e contribui na prevenção de danos que uma atividade cansativa ou prolongada ocasiona ao cérebro e ao corpo. É durante o sono que são eliminadas as toxinas acumuladas no decorrer do dia, além de que, é ele que ajuda na conservação de energia e na promoção de plasticidade do corpo e mente. A privação do sono, comum entre pessoas altamente estressadas, pode produzir uma série de distúrbios orgânicos e mentais, dentre eles: deterioração da memória, distúrbio de aprendizagem, alteração nas funções executivas, lentificação no desenvolvimento do raciocínio matemático, rebaixamento da atenção, comprometimento das tarefas motoras, aumento da sensibilidade à dor, declínio da força muscular, aumento da irritabilidade e fadiga e aumento da possibilidade de desenvolvimento de distúrbios psiquiátricos, neurológicos e cognitivos (VALLE, 2011; BRITTO, 2019).

Durante o dia nosso sistema produz alguns hormônios para ajudar no bom funcionamento do organismo para que possamos ser produtivos e estarmos alertas em nossos afazeres - regulação dos batimentos cardíacos e acionamento dos membros pela tensão muscular. Da mesma forma, há hormônios liberados somente durante a noite e que são responsáveis pela desaceleração dos batimentos cardíacos e relaxamento muscular. Um dos hormônios mais importantes é a melatonina (produzida somente durante o sono profundo e se dormirmos no escuro absoluto), o qual auxilia na eliminação do cortisol produzido no decorrer do dia e na consolidação das memórias (BRITTO, 2019).

Almondes e Araújo (2016) comentam que a secreção de cortisol e da melatonina é realizada corretamente naqueles que possuem um ciclo sono-vigília estável. Ou seja, nossa rotina influencia diretamente na quantidade de liberação dos hormônios reguladores. Então, quando o indivíduo tem uma rotina desajustada, influenciando seu período de sono, há alteração na produção de melatonina e isso faz com que o organismo não entre em estado de relaxamento enquanto dorme. No dia seguinte, um simples estressor pode resultar em um pico de estresse pela ausência de descanso e estabilização dos níveis hormonais do organismo. Além disso, a melatonina contribui na fixação da 
memória, isto é, tudo o que estudamos e vivenciamos durante o dia, é mais bem fixado em nosso sistema nervoso durante o sono. Pouco sono significa pouca melatonina e isso impacta profundamente na saúde e na memória e, por consequência, no nosso comportamento e aprendizado (VAZ, 2013).

Portanto, respondendo à questão colocada anteriormente, sobre como o estresse pode influenciar na nossa saúde física e mental: a partir de alterações químicas em nosso cérebro e corpo, ou seja, pela alteração de áreas cerebrais como o eixo hipotálamohipófise-adrenal, amígdala, hipocampo, dentre outras estruturas. Cabe ressaltar que o estresse é um forte elemento que contribui para o desenvolvimento de transtornos ansiosos e depressivos, mas certamente não é o único fator, bem como nem toda patologia psiquiátrica/psicológica está ligada ao estresse. O estresse é sim um grande fator de risco para o adoecimento físico e mental. No entanto, temos que ter em mente que elementos tais como alimentação, deficiência de vitamina no organismo, predisposição genética, doenças neurológicas, lesões, dentre outras questões, podem também contribuir ou serem os responsáveis pelo adoecimento mental, neurológico ou físico ${ }^{4}$.

Para finalizarmos a discussão sobre o impacto na saúde causado pelo estresse e para contribuir com a compreensão do assunto, devido sua complexidade, criamos uma ilustração sumarizando o conteúdo aqui tratado, baseada no infograma apresentado por Britto (2019, p. 36) em seu trabalho intitulado: Música e Neurociências: o impacto neurofisiológico da rotina do estudante universitário de música.

\footnotetext{
${ }^{4}$ Importante lembrar que o foco deste artigo é o estresse, uma vez que estamos vivendo uma época altamente estressante devido à pandemia e todas as consequências trazidas por ela, por isso não nos ateremos a discutir sobre outras questões que impactam nossa saúde.
} 


\section{O MÚSICO}

\section{Demandas comuns da rotina}

* Falta de tempo para conciliar estudo/trabalho/vida pessoal;

* Ansiedade da performance musical;

* Excesso de estudo e pressão por rendimento e qualidade;

* Instabilidade do mercado de trabalho;

* Investimentos financeiros altos para instrumentos e estudos;

* Competitividade e autocobrança;

\section{Demandas adicionais com o COVID - 19}

*Desmonte da cultura e diminuição significativa das possibilidades de atuação profissional devido ao isolamento;

*Medo de contágio do Coronavírus;

*Perdas: de emprego, da liberdade, de pessoas queridas;

* Dificuldades de adaptação à nova rotina e às ferramentas virtuais para as atividades e aulas;

* Solidão e preocupação com o futuro;

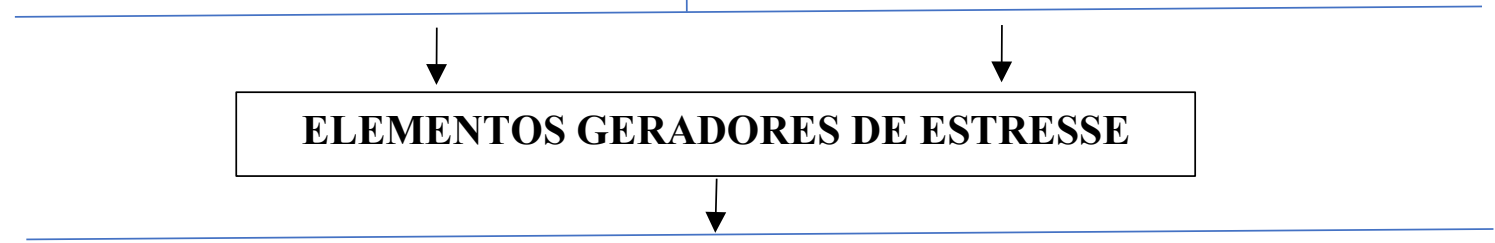

\section{ALTERAÇÕES NEUROBIOLÓGICAS ADVINDAS DO ESTRESSE}

* Aumento da frequência cardíaca, respiratória e da pressão arterial;

* Contração do baço e liberação de glicose pelo fígado;

* Redistribuição sanguínea da pele para o fortalecimento dos músculos (tensão muscular);

* Dilatação dos brônquios e das pupilas e aumento dos linfócitos na corrente sanguínea;

* Hiperativação do eixo hipotálamo-hipófise-adrenal (HPA) - liberação de cortisol em excesso;

* Aumento de cortisol no sistema e diminuição de melatonina (pois o cortisol altera o sono).

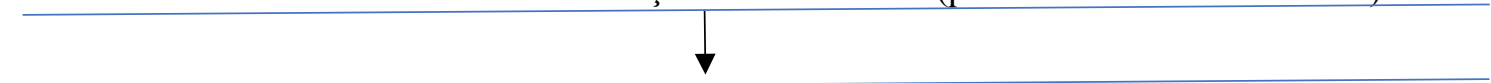

\section{IMPACTO NA SAÚDE DEVIDO ÀS ALTERAÇÕES NEUROBIOLÓGICAS}

*Manifestações de alergias;

*Cansaço em excesso e queda na produtividade;

* Hipertensão;

* Distúrbios gastrointestinais;

* Irritabilidade e agressividade;

* Aumento do risco de depressão e transtornos de ansiedade;

* Alterações do sono;

* Alteração do hipocampo - Problemas de memória;

* Diminuição da atenção e resposta motora;

* Propensão a desenvolvimento de problemas emocionais e cognitivos;

* Dores no corpo/ fadiga. 


\section{Como minimizar os danos do estresse?}

Diante do estresse excessivo precisamos buscar meios de minimizar os danos. Certamente, não é algo simples, uma vez que essas funções neurobiológicas são programadas para funcionarem automaticamente. Isso significa que não temos como controlá-las a partir de nossa vontade, mas, podemos tentar manipulá-las se conseguirmos oferecer ao nosso cérebro informações contrárias às que ele está recebendo do meio ambiente e que está desencadeando o estresse.

Atividades que tragam prazer são fundamentais nesse momento, eliminando o foco do que causa o estresse e aumentar o estímulo das áreas neurológicas ligadas ao prazer ${ }^{5}$. Exercícios físicos, meditação, exercícios de respiração e cultivo de plantas (jardinagem) são alternativas que podem contribuir para a diminuição do estresse. Tentar ser produtivo: estudar, ler, escrever, limpar a casa e promover ações solidárias também pode ajudar o cérebro a criar novas memórias e compreender que não existe somente a pandemia e tudo de negativo que está a ela associado (ARANTES, 2020). Nas palavras de Araújo (2020, p. 30): “o fato de estarmos confinados nos dá a oportunidade de vivenciar o retiro, pois saímos da confusão do dia a dia e assim podemos refletir sobre esse modo de viver a que estávamos acostumados, achando que era o único”. Chiquetti (2020, p. 33-36), completa:

\footnotetext{
Algumas recomendações podem ajudar a manter a saúde mental durante o distanciamento social, tais como:

1 - Focar no presente, adotando uma rotina (adaptada à quarentena, sem exigir-se demais). Importante colocá-la no papel, resguardando tempo para trabalhar, relaxar, ter lazer, se relacionar (mesmo que on-line) etc. A ansiedade leva à necessidade de se deslocar mentalmente para o futuro.

2 - Fazer exercícios diários de respiração. Pratique a respiração profunda e lenta $[\ldots]$

3 - Praticar meditação. Busque adotar esse hábito em sua vida. Comece pelas meditações guiadas (há várias no Youtube e aplicativos destinados a isso) $[\ldots]$.
}

\footnotetext{
${ }^{5}$ Nosso Sistema Nervoso é programado para reagir ao medo, mas também é munido de um sistema para o prazer, chamado Circuito de Recompensa. São áreas neurológicas específicas que lançam dopamina no organismo, promovendo sensação de prazer. O cérebro de pessoas deprimidas produz menos dopamina e serotonina, por isso elas perdem o prazer na vida e ficam desanimadas. Fazer atividades prazerosas é essencial para diminuição do estresse (ESPERIDIÃO-ANTONIO, 2008; LENT, 2010).
} 
4 - Manter sua rede de apoio, mesmo que on-line. Converse com amigos e familiares, compartilhe seus sentimentos com quem acolhe você.

5 - Praticar atividade física. Fundamental para reconectar-se com seu corpo e se manter no tempo presente.

6 - Conectar-se com a espiritualidade. Mantenha a sua prática espiritual, de acordo com sua afinidade. Ou busque uma. Isso ajudará a desenvolver a consciência da unidade com o todo, diminuindo os sentimentos de estar "sem saída" ou "sozinho no mundo".

7 - Buscar ajuda profissional (psicoterapia). Investir em conhecer a si mesmo também significa, além de "colocar as dores para fora", buscar uma vida mais produtiva e assertiva, e identificar e desenvolver os próprios recursos. Cuidar da saúde emocional é favorecer uma cultura de paz mundial, pois quem está bem consigo mesmo está bem com os outros e com tudo à sua volta.

\section{Palavras finais}

Estamos passando por um processo de drástica mudança de rotina, hábitos, comportamentos e cuidado com a saúde. Portanto, sentir medo, insegurança, desânimo, e tristeza é normal. A base de todas essas emoções é o estresse, que como vimos, não é bom nem ruim, mas é um mecanismo automático que nos deixa alerta para a mudança, mas que, em excesso, pode ser danoso à saúde, pois o excesso de cortisol no organismo pode gerar alterações biológicas significativas. Portanto, cabe a nós, diariamente, treinarmos nosso cérebro para aprender a lidar com o estresse e com isso, diminuir o risco de adoecimentos mais graves.

\section{Referências}

AGÊNCIA IBGE NOTÍCIAS. Participação da cultura no orçamento reduz em todas esferas de governo em 2018. Reportagem do Sistema de Indicadores Culturais do IBGE, 05 de dezembro de 2019. Disponível em: https://agenciadenoticias.ibge.gov.br/agencia-noticias/2012-agencia-denoticias/noticias/26238-participacao-da-cultura-no-orcamento-reduz-em-todas-esferas-degoverno-em-

2018\#: :text=Participa\%C3\%A7\%C3\%A3o\%20da\%20cultura\%20no\%20or\%C3\%A7amento\% 20reduz\%20em\%20todas\%20esferas\%20de\%20governo\%20em\%202018,Editoria\%3A\%20Estat $\% \mathrm{C} 3 \%$ ADsticas $\% 20$ Sociais\&text $=\mathrm{O} \% 20$ setor $\% 20 \mathrm{p} \% \mathrm{C} 3 \% \mathrm{BAblico} \% 20 \mathrm{~d}$ estinou $\% 20$ para,despesas $\% 20$ consolidadas $\% 20 \mathrm{da} \% 20$ administra $\% \mathrm{C} 3 \% \mathrm{~A} 7 \% \mathrm{C} 3 \% \mathrm{~A} 3 \mathrm{o} \% 20 \mathrm{p} \% \mathrm{C}$ 3\%BAblica. Acesso em: 31 de out. de 2020. 
ALHEIRA, Flávio; BRASIL, Marco Antônio. O papel dos glicocorticóides na expressão dos sintomas de humor: uma revisão. Revista de Psiquiatria, RS maio/ago, 2005; v. 27, n. 2, p. 177186.

ALMONDES, Katie Moraes de; ARAÚJO, John Fontenele de. Padrão do ciclo sono-vigília e sua relação com a ansiedade em estudantes universitários. Estudos de Psicologia, Rio Grande do Norte, v. $1, \quad$ n. $8, \quad$ p. 37-43, 2003. Disponível em: http://www.scielo.br/pdf/\%0D/epsic/v8n1/17233.pdf. Acesso em: 29 de set. de 2020.

ARANTES, Mariana (org). Pandemia e Pandemônio: reflexões sobre educação emocional em tempos de coronavírus. Recife: Editora UFPE, 2020, p. 44-47.

BACON, Peter. $64 \%$ musicians considering leaving the music profession. London Jazz News, Londres, 24 de agosto de 2020. Disponível em: https://londonjazznews.com/2020/08/24/64musicians-considering-leaving-the-music-profession-survey/. Acesso em: 31 de out. de 2020.

BARROS, M. H. F. (2020). Educação musical, tecnologias e pandemia. OuvirOUver, v. 16, n. 1, p. 292-304.

BRITTO, Priscylla Souza. Música e Neurociências: O impacto neurofisiológico da rotina do estudante universitário de música. 2019. 45 f. TCC (Graduação) - Curso de Música, Departamento de Música, Universidade Federal de Pernambuco, Recife, 2019.

CALABRE, Lia. A arte e a cultura em tempos de pandemia: os vários vírus que nos assolam. Extraprensa, São Paulo, v. 13, n. 2, p. 7-21, jan./jun. 2020.

CHIQUETTI, Taciana. Distanciamento social: da ansiedade ao amadurecimento emocional. In: ARANTES, Mariana (org). Pandemia e Pandemônio: reflexões sobre educação emocional em tempos de coronavírus. Recife: Editora UFPE, 2020, p. 33-37.

ESPIRIDIÃO-ANTONIO, Vanderson, et al. Neurobiologia das emoções. Rev. Psiquiatr. Clín., v. 35, n. 2, p. 55-65, 2008. https://doi.org/10.1590/S0101-60832008000200003.

FERNANDES, M. A.; RIBEIRO, H. K. P.; SANTOS, J. D. M.; MONTEIRO, C. F. S.; COSTA, R. S.; SOARES, R. F. S. Prevalência de transtornos de ansiedade como causa de afastamento de trabalhadores. Revista Brasileira Enfermagem, v. 71, supl. 5, Brasília, 2018, p. 2344-2351.

FONTANA, David. Estresse: faça dele um aliado e exercite a autodefesa. São Paulo: Saraiva, 1991.

GRANER, Karen Mendes; CERQUEIRA, Ana Teresa de Abreu Ramos. Revisão integrativa: sofrimento psíquico em estudantes universitários e fatores associados. Ciênc. saúde coletiva, Rio de Janeiro, v. 24, n. 4, p.1327-1346, 2019.

GUERRA, Mariana. Ansiedade. Disponível em $<$ https://mariangelaguerra.com.br/> Acesso em: 5 set. 2020.

JOCA, Sâmia et al. Estresse, depressão e hipocampo. Revista Brasileira de Psiquiatria 2003; v. 25, Supl. II, p. 46-51.

KANDEL, Eric R. et al. Princípios de Neurociências. 5. ed. Porto Alegre: Amgh, 2014. 
LENT, Roberto. Cem bilhões de neurônios?: Conceitos fundamentais de neurociências. 2. ed. Rio de Janeiro: Atheneu, 2010.

LOURO, Viviane. Estresse e educação emocional pela neurociências. In: ARANTES, Mariana (org). Pandemia e Pandemônio: reflexões sobre educação emocional em tempos de coronavírus. Recife: Editora UFPE, 2020, p. 44-47.

NOAL, Débora; DAMÁSIO, Fabiana (Coord.). Saúde mental e atenção psicossocial na pandemia COVID-19. Ministério da Saúde: FIOCRUZ, 2020.

ORGANIZAÇÃO MUNDIAL DA SAÚDE (OMS). Depression and Other Common Mental Disorders: Global Health Estimates. Geneva: World Health Organization; 2017. Licence: CC BY-NC-SA 3.0 IGO.

ORGANIZAÇÃO PAN-AMERICANA DA SAÚDE (OPAS). ONU destaca necessidade urgente de aumentar investimentos em serviços de saúde mental durante a pandemia de COVID-19. 14 de maio de 2020.2 Disponível em: https://www.paho.org/bra/index.php?option=com_content\&view=article\&id=6170:onu-destacanecessidade-urgente-de-aumentar-investimentos-em-servicos-de-saude-mental-durante-apandemia-de-covid-19\&Itemid=839. Acesso em: 15 de out. de 2020.

ROZENTHAL, Marcia. Aspectos neuropsicológicos da depressão. Revista Psiquiatria. RS, 26'(2): 204-212, mai./ago. 2004.

SELYE, Hans. The Evolution of the Stress Concept: The originator of the concept traces its development from the discovery in 1936 of the alarm reaction to modern therapeutic applications of syntoxic and catatoxic hormones. American Scientist. Carolina do Norte - Estados Unidos, p. 692-699. dez. 1973.

TENG, Chei T.; PAMPANELLI, Mariana. O suicídio no contexto psiquiátrico. Revista Brasileira de Psicologia, v. 2, n. 1, Salvador, Bahia, 2015, p. 41-51.

VASCONCELOS, Ana. O Cérebro Social: Compreendendo o Cérebro Como um Órgão Social. Interações: sociedade e as novas modernidades 32. Pp. 34-52, 2017.

SPAHN, Claudia; RICHTER, Bernhard. Avaliação do risco de contaminação com COVID-19 em Instrumentistas e Cantores. Terceira atualização. Alemanha: Instituto de Música e Medicina da Universidade de Medicina e da Universidade de Música de Freiburg, 1 de junho de 2020.

VALLE, Luiza. Estresse e distúrbios do sono no desempenho de professores: saúde mental no trabalho. Tese de doutorado. Instituto de psicologia da USP. São Paulo: USP, 2011. (209 p).

VAZ, F. C. et al. Cortisol e atividade física: Será o estresse um indicador do nível de atividade física espontânea e capacidade física em idosos? Revista Brasília Médica, São Paulo, 50, n.2, p. 143-152, 2013. 